\title{
Outside the Comfort Zone: Strategies for Developing Emotionally Intelligent Leaders
}

\author{
Michael J. Liepold \\ Extension Professor \\ Extension Center for Community Vitality \\ University of Minnesota \\ mliepold@umn.edu \\ Catherine M. Rasmussen \\ Extension Professor \\ Extension Center for Community Vitality \\ University of Minnesota \\ rasmu035@umn.edu \\ Kim Boyce \\ Regional Director - Central Region \\ Extension Professor \\ University of Minnesota \\ boyce003@umn.edu \\ Denise Trudeau Poskas, Ph.D. \\ Associate Professor and Leadership Specialist \\ Extension Center for Community Vitality \\ University of Minnesota \\ dtrudeau@umn.edu
}

\begin{abstract}
A recent study of the Minnesota Agriculture and Rural Leadership (MARL) program set out to determine the relationship between andragogical program design and increased levels of emotional intelligence (EI). Members of two cohorts in the MARL leadership development program received different levels of focused effort, peer coaching, individual action plans, disorienting dilemmas, self-reflection, and training in the area of emotional intelligence. We examined four years of data, including participants' results on the Bar-On Emotional Quotient Inventory (EQ-i) before and after undergoing leadership development training, as well as their individual reflections on the EI components of their training. The intention is that this research will encourage practices that seek to increase emotional intelligence in leaders.
\end{abstract}

\section{Introduction}

As technological and other factors increase the pace of change in today's world, there is a greater need than ever before to enhance leaders' ability to handle complex situations, communicate clearly, and to maintain an even temperament in emotionally-charged situations. To meet this 
need, University of Minnesota Extension strives to instill individuals with effective leadership skills. Extension's U-Lead cohort leadership programs have a strong track record of building cognitive and analytical skills.

Building on this foundation one of Extension's U-Lead programs, the Minnesota Agriculture and Rural Leadership (MARL) program, recently introduced emotional intelligence (EI) skills to its training curriculum. Salovey and Mayer (1990) coined the term emotional intelligence and defined it as a social intelligence involving the ability to monitor the thinking and actions of an individual and others. With increasing pressures in the workplace and in the community, the ability of a leader to deal with daily emotional demands is even more critical.

Additionally, a growing body of research demonstrates that emotional intelligence is a predictor of success in leadership roles - with success defined as changing followers' behaviors in a positive way. The ability to recognize one's own and others' emotions and maintain a positive affect and agreeable manner in tense situations has predicted transformational leadership behavior (Rubin, Munz, \& Bommer, 2005). Further, unlike cognitive intelligence, emotional intelligence can be increased by focused effort, coaching, and training in specific areas (Pearman, 2006; Cherniss, 2010). To demonstrate this assertion, this study analyzed results from two cohorts of a University of Minnesota Extension leadership development program that had incorporated emotional intelligence as a core leadership theme. The study measured the success of leadership development programming in strengthening emotional intelligence and it identified the specific teaching strategies that were the most beneficial for producing emotionally intelligent leaders.

\section{Literature Review}

Existing research has shown that an individual's emotional intelligence quotient (EQ) can better predict success in both professional and personal pursuits than the cognitive intelligence quotient or IQ (Goleman, 1995). Multiple studies have shown that EI competencies often account for the difference between star performers and average performers, particularly in positions of leadership (Durek \& Sheldon, 2009). The United States Air Force is just one of many organizations that use EI assessments and trainings to improve retention, increase productivity, improve performance and achieve savings in time and money (Bar-On, 2006).

As EI continues to grow in both literature and application most research demonstrates that EI is teachable and essential to leadership (Goleman, 1996; Steiner, 1997; Higgs, 2004; Höpfl \& Linstead, 1997; Cooper, 1997; Martinez, 1997). Emotionality in leadership impacts decision making and leadership styles making it central to group experiences and results. For instance, when stressful situations cause negative emotions to be prevalent in groups not only are the leaders' emotional reactions important, but their capability to regulate their own emotions in team settings proves to be vital as well (Chemers, Hays, Rhodewalt, \& Wysocki, 1985). What is crucial in lowering job stress and health problems among employees and other groups is the match between leadership style and the situation (Higgs, 2004; Fineman, 1997; Höpfl \& Linstead, 1997). 
As the amount of literature regarding the EI capacity of leaders has increased, so has the need to understand how to design leadership programs to create the optimum environment for enhancing EI attributes. Thus, a growing amount of literature is devoted to processes and programs designed to develop participants' EI (Martinez, 1997; Farnham, 1996; Harrison, 1997; Cooper, 1997).

Research showing developmental growth in EI has become much more prevalent. For example, Dulewicz and Higgs (2004) demonstrated developmental growth in EI in three studies with various participant groups. Their study demonstrated that EI can be influenced by experiences. Data from their research was used in the Bar-On EQ-i and two other EI questionnaires.

Likewise, emotionality is prevalent in the field of leadership as leaders have been theorized to affect the behavior of their followers. This is relevant not only in individual factors, but may have implications for team dynamics and emotional intelligence. In 2003, Jing Zhou and Jennifer George wrote an article saying that the "root of creativity-supportive leadership behaviors is emotional intelligence" (Zhou \& George, 2003). Research clarifies that a key contextual factor influencing employee creativity is leadership (Shin \& Zhou, in press; Tierney, Farmer, \& Graen, 1999).

In their study, Höpfl and Linstead (1997) assert that the core capabilities of leaders are developed in early life. At the same time, work experiences have a strong impact on this shaping process. In developing this argument, they contend that what managers learn in an organization includes learning about their feelings regarding what they learn and do in the organization and that the emotional dimension of the work of management is reflected through working experiences and practices. Their study brings to light the importance of using forms of transformative learning practices to produce an increase in several subscales of EI.

A study by Barbuto (2009) indicates that leaders with high EI will also be strong in developing relationships that promote greater flow of information, sharing of influence, increased confidence and concern for followers, and achieve more highly involved and more communicative followers.

Another important study is one by Slaski and Cartwright (2002) that examined the relationship between emotional intelligence, stress, well-being, and performance. This study of 224 managers in a large retail organization evaluated the ability of a leadership education program to develop emotional intelligence. The program worked to develop the areas of self-awareness, detachment, regulation of one's own emotions and recognition of emotions in others. Results showed a statistically significant improvement both on the EQ total score and on five of the seven elements at the 0.001 level (unless indicated otherwise).

At the end of the training program, improvements were noted in self-awareness, interpersonal sensitivity, influence ( 0.01 level), motivation ( 0.01 level), and emotional resilience. Slaski and Cartwright (2002) reported that the program constructs used to create this positive impact on emotional intelligence scores were forms of cognitive stimulation, such as lectures and 
discussions, as well as application and synthesis activities like role-plays, journals, and dialogue. Managers were retested again on their EQ six months after the final day of training.

The literature linking EI and leadership development suggests that programs need specific structures in order to achieve significant progress in improving emotional intelligence. Programs that show a positive impact on EI scores have five elements in common:

- A baseline assessment in which participants use a self-report or 360-degree feedback mechanism to assess their emotional intelligence.

- Participants use a structured action plan to guide their self-development, as well as hold themselves accountable.

- Some form of group or individual coaching.

- New knowledge or cognitive stimulation on the topic of emotional intelligence and leadership.

- Small group support to build individual efficacy in emotionally intelligent leadership. (Boyatzis \& Van Oosten, 2002; Caruso \& Salovey, 2004)

As we will discuss below in the Methodology section, we began our study of MARL participants with each of these strategies for promoting emotional intelligence in mind. We found that small group dynamics, cognitive stimulation, and transformative learning were the major constructs that built the foundation for change in participants. In addition to these strategies, however, was the observation that a disorienting dilemma is often the initiating factor in a transformational learning process (Mezirow, 1991). The sense of being moved outside of one's comfort zone often leads to the type of self-reflection that increases overall emotional intelligence and leadership capacity. Thus, we decided to include the concept of moving people out of their comfort zones in our study.

\section{Methodology}

This study employed a mixed methods approach (Tashakkori \& Teddlie, 1998) to triangulate quantitative and qualitative methods (Denzin, 1989; Patton, 2002). Quantitative findings from the EQ-i pre- and post-surveys were combined with qualitative interview data from the five participants in each cohort who made the greatest gains in their EQ-i scores.

\section{Study Participants}

Our study included 64 participants: 32 members of MARL Class 5 and 32 members of MARL Class 6. MARL Class 5 was held November 2008-March 2010. MARL Class 6 was held November 2010-March 2012. Participants were chosen based on the quality of their application, reference checks, and interviews. The MARL Board of Directors made the final selection. The average age of participants in Class 5 was 45, with 59\% holding college degrees. There were 24 males and 8 females. The average age of participants in Class 6 was 46, with $69 \%$ holding college degrees. In this group, 21 were male and 11 female. 


\section{Cohort and Research Design}

While strategies intended to enhance EI were integrated into the curriculum of both MARL classes, Class 6 included more strategies and a higher frequency of EI training than Class 5.

Class 5 participants were introduced to the topic of EI in a 3.5 hour seminar at the first session. The 32 cohort participants then completed the EQ-i online. Each participant received an individualized report and was personally debriefed on their results by a certified EQ-i administrator (one of the four authors of this article).

During the second session of the program, Class 5 participants created individual development plans and identified specific behaviors to change. Each participant was encouraged to meet with two to three others in the class to share plans and get together as needed outside class to support one another in carrying out their plans. At the conclusion of the 18-month program, participants again completed the online instrument and were debriefed by the same author.

Group summaries of both the pre- and post-EQ-i results were generated by Multi-Health Systems, Inc. C and compared. Individual results were compared using a paired samples test on each of the subscales. Qualitative findings were gathered on participants' perceived degree of change through exit interviews and post-program surveys. Results revealed that although the majority of participants found value in improving their emotional intelligence skills, very few of them met within small groups for support outside class.

Class 6 participants completed the Bar-On EQ-i online prior to and following the 18-month program and were debriefed by the authors in the same manner as Class 5. However, Class 6 design included focused efforts on improving EI skills that Class 5 did not. Focused efforts featured intervention strategies, peer coaching, and EI skills practice. These focused efforts included:

- Small Group Dynamics. The Class 6 cohort was divided into groups of three, or triads. The authors intentionally assembled these triads based on each participant's areas of strength and areas for development. For example; a participant high in flexibility might be assigned to a triad with a participant needing development in that same area. Thus, in each triad a participant would have something to share and something to learn. Each member of a triad shared a personal development plan with the group and provided each other with support and coaching for individual change. They were instructed on how to do this. Triads met regularly throughout the 18-month program for personal reflection and peer monitoring. As participants became more experienced with the triads, they began to give assignments to each other. For example, a participant intent on improving impulse control was told to try waiting for at least two other people to speak before refuting another speaker's point of view.

- Cognitive Stimulation. The topics of ethnography, impression management, social awareness, self-management, and self-awareness were added to the curriculum for Class 6 participants. Additional training in the area of EI itself asked participants to research 
ways to improve areas of weakness and relative strength. Many of the strategies were included in their personal development plans. Suggested readings provided additional background. Experiential activities were assigned to participants so they could practice new skills and reinforce developmental progress. Participants recorded their progress through journaling.

- Transformative Learning. Even before we conducted this study, the MARL program included a variety of experiential activities that encouraged them to move out of their comfort zones. An example might be to meet with a member of the United States Congress or walk the narrow alleys of the medina section of a Moroccan city for the first time. These disorienting dilemmas cause stress and even panic, but they can give participants the opportunity to find meaning in the situation. Personal reflection and discussion with others in the group provide a whole new level of learning (Mezirow, 1991). Each experience was designed to simultaneously challenge and affirm participants.

\section{Quantitative Inquiry}

The quantitative data compared the differences in the mean of EI scores of two cohorts - MARL Class 5 and Class 6 . The analysis was done by administering pre- and post-assessments of participants using the Bar-On EQ-i. Developed by Reuven Bar-On (2006), the EQ-i is a selfreporting, skill-based model of EI. The instrument has been shown to be a strong predictor of success in increasing individual EI and is the most commonly used tool for measuring changes in EI.

The EQ-i consists of 133 relatively short statements in which responses are provided on a 5-point Likert scale ranging from "Very often true of me" or "True of me" to "Very seldom true of me" or "Not true of me." The EQ-i raw scores are converted into standard scores based on a mean of 100 and a standard deviation of 15 (Bar-On, 2006). The total EQ-i score breaks down into 15 subscales that are categorized into five composite scales: Intrapersonal, Interpersonal, Stress Management, Adaptability, and General Mood.

A total EQ-i score above 100 or a higher-than-average score on any individual composite or subscale implies stronger EI skills and is a positive predictor for effective functioning in meeting demands and challenges in that particular content area. A lower EQ-i score implies poorer EI skills and a reduced ability to be effective in meeting demands and challenges. (Bar-On, 1997)

\section{Qualitative Inquiry}

Qualitative data were gathered at the end of the 18-month formal cohort program. All participants from Class 5 and 6 answered open-ended questions in written surveys and individual video-taped interviews. Feedback was collected on the value of the EQ-i instrument, the skills participants worked on, and the degree to which they observed successful change. They were asked to identify specific experiences or strategies that contributed to the change in their EI. 
Additionally, post-cohort reflective interviews using Brinkerhoff's (2006) Success Case Method were conducted. Using the data on increases in EQ-i total scores, the top five participants from the two MARL classes were identified. Four of the five individuals were participants in Class 6 . Each of the five were interviewed by phone and were asked about the aspects of the program that they believed had contributed the most to their increased EQ-i results. Probing questions were used to identify strategies that they implemented within the cohort, with their triad, or in their everyday lives that they felt affected the change in their EI score.

\section{Findings}

Both classes of the MARL program showed statistically significant improvement at a $p<0.05$ level on a paired-samples $t$-test using SPSS. Figure 1 shows the average Total EQ score for participants in Class 5 was 99.4 at the beginning of the program and increased by 3.8 points to 103.2 at the end of the program. Class 6 participants began the program with an EQ-i of 101.9 and ended the program with an average of 106.5 for a 4.6-point increase.

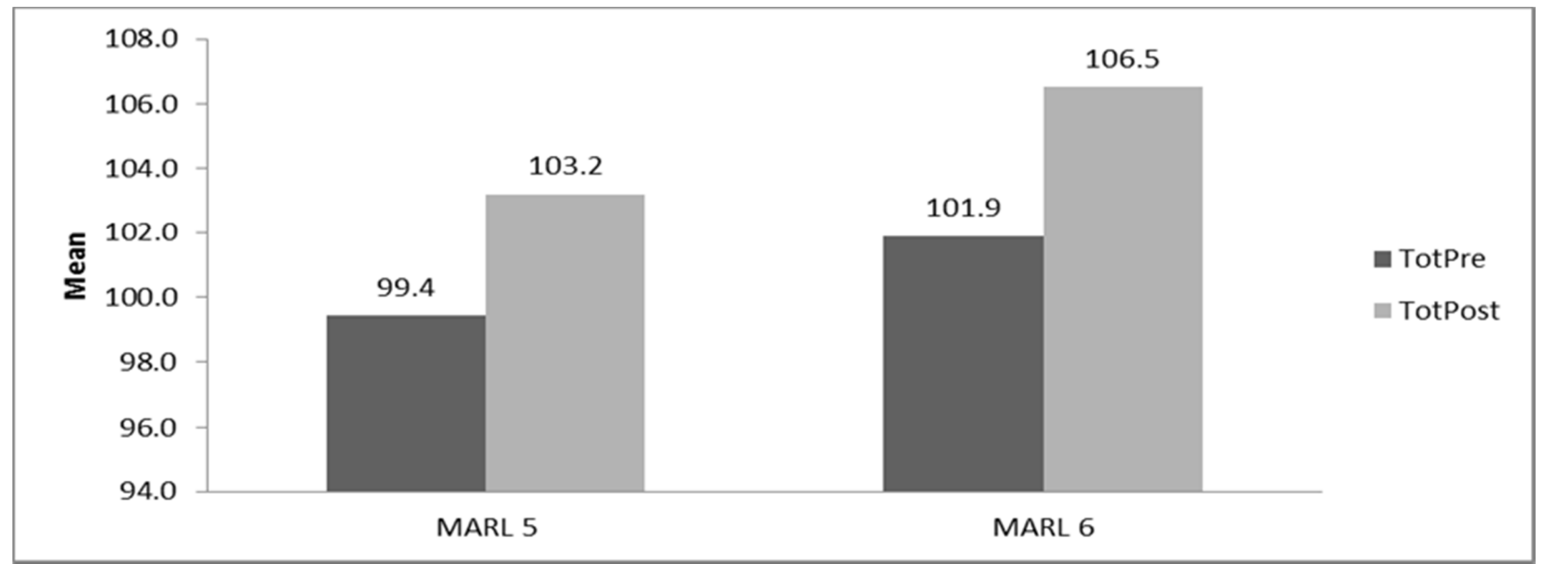

Figure 1. Total EQ change MARL Class 5 vs. Class 6.

Table 1 presents the mean scores for each of the EQ-i survey scales and subscales for both MARL Classes 5 and 6. The EQ-i measures five core scales: Intrapersonal, Interpersonal, Stress Management, Adaptability, and General Mood. Each MARL class saw significant increases in four of these five scales. Both groups experienced significant change in three of the scales: Intrapersonal, Stress Management and Adaptability. Class 5 saw a significant $(p<0.01)$ increase in the General Mood scale while Class 6 did not. Class 6 experienced a significant $(\mathrm{p}<0.01)$ increase in the Interpersonal scale while Class 5 did not.

Table 1

Pre- \& Post-Emotional Intelligence Scores MARL Classes 5 and 6 


\begin{tabular}{|c|c|c|c|c|c|c|}
\hline Scales/Subscales & Class 5 Pre-Mean & Class 5 Post-Mean & Sig. level5 & Class 6 Pre-mean & Class 6 Post-Mean & Sig. level6 \\
\hline Total EQ & 99.4 & 101.2 & 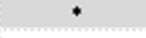 & 101.9 & 106.5 & * \\
\hline Intrapersonal & 100.0 & 104.1 & $\bullet *$ & 102.7 & 106.1 & * \\
\hline Self-Regard & 100.5 & 102.8 & NS & 101.2 & 103.3 & NS \\
\hline Emotional Self Awareness & 99.6 & 101.8 & $* *$ & 99.3 & 105.5 & $* *$ \\
\hline Assertiveness & 99.5 & 104.1 & $*$ & 104.2 & 105.8 & NS \\
\hline Independence & 103.2 & 105.5 & NS & 107.1 & 107.7 & NS \\
\hline Self-Actualization & 101.0 & 103.7 & NS & 101.6 & 103.3 & NS \\
\hline Interpersonal & 98.3 & 99.7 & NS & 100.1 & 104.8 & * \\
\hline Empathy & 98.7 & 101.2 & NS & 97.0 & 103.5 & $* *$ \\
\hline Social Responsibility & 100.6 & 101.1 & NS & 104.2 & 105.9 & NS \\
\hline Interpersonal Relationship & 97.9 & 99.5 & NS & 99.6 & 103.7 & NS \\
\hline Stress Management & 99.3 & 102.9 & + & 100.8 & 108.1 & $+*$ \\
\hline Stress Tolerance & 100.3 & 104.8 & * & 102.6 & 109.3 & * \\
\hline Impulse Control & 98.6 & 100.1 & NS & 98.7 & 104.5 & * \\
\hline Adaptability & 99.5 & 103.4 & * & 99.1 & 104.0 & - \\
\hline Reality Testing & 100.7 & 104.2 & NS & 104.6 & 105.7 & NS \\
\hline Flexibility & 95.9 & 98.4 & NS & 92.7 & 99.5 & $* *$ \\
\hline Problem Solving & 102.2 & 105.8 & $* *$ & 99.8 & 104.6 & $*$ \\
\hline General Mood & 101.8 & 105.3 & $*$ & 103.2 & 106.1 & NS \\
\hline Optimism & 102.6 & 105.9 & $*$ & 105.7 & 106.6 & NS \\
\hline Happiness & 101.8 & 105.0 & NS & 101.5 & 105.7 & $*$ \\
\hline & & ${ }^{*} p<.05 \quad{ }^{* *} p<.01 \quad N S$ & Not significant & & & \\
\hline
\end{tabular}

Within each of the five core scales, the EQ-i measures change in 15 subscales. Class 5 reported significant increases in five of these subscales: Emotional Self Awareness, Assertiveness, Stress Tolerance, Problem Solving, and Optimism. Class 6 reported significant changes in seven subscales: Emotional Self Awareness, Empathy, Stress Tolerance, Impulse Control, Flexibility, Problem Solving, and Happiness.

Impulse Control and Happiness, two of the subscales found to change significantly in Class 6 but not Class 5, have been identified as influential factors in leadership success (Durek, 2006).

\section{Qualitative Interview Data}

What role did the specific interventions offered by MARL play in the increased EI of program participants? The Success Case method focuses on describing strategies that the most successful individuals found to be important (Brinkerhoff, 2006). Stories of EI learning from the five most improved MARL participants from Classes 5 and 6 provide a richer understanding of the curriculum aspects that produced success. The names and identifying characteristics of each individual have been changed to insure their anonymity. The five biggest changers were each asked the following questions:

- What factors contributed to your success?

- Specifically what did you do?

- What support did you rely on, if any?

- What aspects of the MARL program contributed to your personal gains, if any?

- How has MARL changed you on a personal level if at all? 
Don was in Class 6, and his total EQ-i score went from 91 to 111. He focused on the importance of the triad support team in shaping his EI. When asked the question, "How has MARL changed you on a personal level?" Don responded, "Tremendously! The EQ-i Assessment - huge, huge, huge, huge, and that test knows you! It's almost shocking how well that tells you about your personality - the way you work and the way you think. When I was younger I got really stressed out about many, many things and I think by taking this test, and being in this program, working with my triad and having a support team to say let's work through some of these weaknesses to make you a better person, I think that really helped improve that and just to become more aware. On a personal level - in stressful situations you can just say ok, let's just take a timeout here and think about this before reacting and have adverse consequences. Let's just think about what's going to happen."

Bob was in Class 5, and his total EQ-i score went from 93 to 115 . He emphasized the importance of the new self-knowledge he gained from the EQ-i assessment. The EQ-i identified the unhappiness in Bob's life. It was specific and dramatic. Bob did not want to believe it. He knew he was unhappy, but did not realize the extent of his discontent before taking the assessment. After learning that happiness is a very important quality of a leader, he accepted that he needed to change. It seemed logical to him that no one wants to be around a negative person, much less follow such a person. He sought support for development from his spouse and took advantage of the 45 contact days with members of his MARL cohort to observe and learn from them. He watched how they interacted, noticing that the happiest people seemed to meet others and make small talk easily. So he practiced making small talk and soon improved. Bob found that the more focused he was on listening, the less anxiety he had and the easier it became. Bob expected big improvements in General Mood and Stress Management. The final survey reflected his efforts. But what he did not expect was the modest improvements in all other categories. Bob now realizes that he has an addictive personality that can lead to gambling, overeating, and depression. He has pledged to work on his Stress Management and Impulse Control for the rest of his life.

Haley was in Class 6, and her total EQ-i score went from 81 to 104 . Working 25 years as a social worker for an adult chemical dependency treatment center calloused Haley to people and their problems. She found it difficult to commit to long term relationships. At the beginning of the leadership program, she felt overwhelmed and was certain she did not belong there. However, she said taking the EQ-i assessment was one of the best things she has ever done. After the first time she took the assessment, Haley was concerned about her scores. Her Social Responsibility rating was markedly low, so she created her personal development plan around it. She credits her triad with providing the most significant support in helping her improve her EI. She said, "We complemented each other's strengths and areas for improvement. We were an incredible match. I feel our international study tour to Morocco definitely helped my empathy. I will continue working at this to make me a better person, wife, grandmother and citizen."

Matt was in Class 6, and his total EQ-i score grew from 92 to 122 . He came to the MARL program with years of successful experience in educational administration. Despite his successes, he was at a low point in his career. Differences in styles and vision within the leadership team at his workplace had taken its toll. Matt was beaten down and discouraged. The 
program and the EI curriculum was just what he needed; the training gave him time to think about his direction in life and work to improve himself. MARL provided an opportunity to reflect, build positive relationships, and receive lots of encouragement and support from members of his triad. Understanding his emotional strengths and weaknesses helped him analyze his issues and develop a plan of action to instigate positive personal change. A part of his plan called for reducing time spent in arenas where he has less control and influence.

Carl was in Class 6, and his total EQ-i score went from 101 to 121 . He came to the MARL program expressing a strong desire to learn. An 18-month cohort program was the perfect laboratory where he could try new things and find out if they work. "You could watch people with differing perspectives, opinions and ways of interacting," he said. The EI assessment was useful in pinpointing his personal traits and developing a plan for self-improvement. "It's nice to put a value on emotions, place it on a scale and be able to compare. It [the assessment] showed areas I needed to work on," he said. The program provided Carl a framework to observe other leaders in action and see how their strategies and personal characteristics affected their success as a leader. The international study tour pushed Carl out of his comfort zone. Morocco opened his eyes to the differences in agricultural production and the gender expectations of Moroccan society.

\section{Discussion}

This study was designed to determine to what degree the use of differing program content and design would affect the development and use of EI as measured by the Bar-On EQ-i in a cohort leadership group. The scope and scale of the educational content and interventions were varied for two consecutive cohort groups participating in the MARL program.

Data indicate that the cohort group receiving a greater amount of EQ-i-related content and interventions saw significant change on seven of the EQ-i subscales, while the cohort group receiving a lesser amount of EQ-i-related content and interventions showed significant change on only five EQ-i subscales. Both groups experienced significant change in three EQ-i subscales: Emotional Self Awareness, Stress Tolerance, and Problem Solving. The group receiving less EQ-i-related educational content and interventions saw significant change in two additional EQ-i subscales - Assertiveness and Optimism. The group receiving a greater amount of EQ-i-related content and interventions showed significant change in four additional EQ-i-related sub-scales Empathy, Flexibility, Impulse Control, and Happiness.

It is worth noting that the Impulse Control and Happiness scales are two of the scales most closely linked with leadership success (Durek, 2006). Both groups received similar content and interventions, including an individual briefing on their personal EQ-i results, instruction on the EQ-i and EI concepts, creation of a personalized EI development plan, and the opportunity to participate in discussions and reflect on questions and observations related to EI. In both groups, the introduction of EQ-i scores and EI concepts provided measurable benchmarks and a new set of terms that were used to analyze and discuss EI observations and behaviors. 
Nevertheless, the group receiving a greater amount of EQ-i-related content and interventions demonstrated both quantitative and qualitative positive differences. Intentionally assigning participants to triads, introducing additional elements of additional small group dynamics to the triads, adding more activities to provide cognitive stimulation related to EI, practicing specific experiential learning activities and reflecting on the results of those activities, and deliberately linking EI concepts to intercultural experiences all yielded greater levels of change in this MARL cohort compared with the other.

\section{Conclusions and Implications}

The results of this study support and affirm earlier literature that asserts that EI can be increased. Our study reinforces the importance of using intentional, recurrent program design elements to consistently support the desired change in EI of emerging leaders. The results of this study reinforce and expand the key components of leadership program design as identified by Boyatzis and Van Oosten (2002) and Caruso and Salovey (2004). When designing leadership programs, educators and practitioners need to provide as the foundation the major constructs:

- Small group dynamics.

- Cognitive stimulation.

- Transformative learning.

Forcing participants outside their comfort zone proved to be a supportive element in increasing EI. Constructing experiences designed to provide simultaneous challenge and support is most effective. When participants have established a safe zone in which to learn, they are more willing to voluntarily move outside their comfort zone and support others who are willing to do the same. Similarly, developing specific experiential activities that allowed participants to practice new skills, receive immediate constructive feedback on their behaviors, and then reflect and record their experiences in their journals, provided a regular way for participants to monitor and chart their progress. A higher level of self-awareness creates an environment of deeper awareness of others. Again, this creates a solid environment for simultaneously providing challenge and support to other participants.

All 11 MARL seminars over the course of the 18-month program included the topic of EI; however, intervention strategies varied in intensity and time between the two MARL Classes. The increased frequency and intensity of participation in the learning triads in Class 6 resulted in larger improvements in EQ-i scores than in Class 5. Another implication for leadership practitioners is the importance of the method that is used to determine triads. Assigning participants to their triads based on their areas of strength and areas for development resulted in greater success than allowing participants to self-select their own groups. In addition, triad members should be coached to share personal development plans and both challenge and support the learning objectives of others in the triad. Setting clear expectations and allowing participants to repeatedly interact with each other established a level of mutual trust and made the triad a safe place to work on improving their EI. 
Leadership educators can achieve significant change in the EI of cohort participants by strategically incorporating these components throughout the entire program. Increasing EI requires focused effort, peer coaching, individual action plans, disorienting dilemmas, selfreflection, and training in the area of EI.

\section{References}

Barbuto, J. E. (2009). The emotional intelligence of leaders as antecedent to leader-member exchanges: a field study. Journal of Leadership Education, 8(2) 135-144.

Bar-On, R. (1997). The emotional quotient inventory (EQ-i). Technical Manual. Toronto Multi Health Systems.

Bar-On, R. (2006). The Bar-On model of emotional-social intelligence (ESI). Psicothema, 18, supl., 13-25.

Boyatzis, R. E., \& Van Oosten, E. (2002). Developing emotionally intelligent organizations. International Executive Development Programmes ( $7^{\text {th }}$ ed.). London: Kogan Page Publishers.

Brinkerhoff, R. O. (2006). Telling training's story. San Francisco: Berrett-Koehler.

Mayer, J. D., Salovey, P., \& Caruso, D. R. (2004). Emotional intelligence: Theory, findings, and implications. Psychological inquiry, 15(3), 197-215.

Ayman, R., Chemers, M. M., \& Fiedler, F. (1995). The contingency model of leadership effectiveness: Its levels of analysis. The Leadership Quarterly, 6(2), 147-167.

Cherniss, C. (2010). Guidelines for securing organizational support for emotional intelligence efforts. Retrieved from http://www.eiconsortium.org/reports/guidelines_for_securing_org_support.html

Cooper, R. K. (1997). Applying Emotional Intelligence in the Workplace. Training and Development, 51(12), 31-38.

Denzin, N. (1989). The research act: A theoretical introduction to sociological methods $\left(3^{\mathrm{rd}} \mathrm{ed}.\right)$. Englewood Cliffs, NJ: Prentice-Hall.

Dulewicz, V., \& Higgs, M. (2004). Can emotional intelligence be developed? The International Journal of Human Resource Management, 15(1), 95-111.

Durek, D., \& Sheldon, S. (2009, August 5). Selecting emotionally intelligent leaders for a competitive advantage. Training. Retrieved from http://www.trainingmag.com/article/selecting-emotionally-intelligent-leaderscompetitive-advantage 
Farnham, A. (1996). Are You Smart Enough to Keep Your Job? Fortune, 133(1), 34-36.

Fineman, S. (2003). Understanding emotion at work. London: Sage.

Goleman, D. (1995). Emotional intelligence: Why it can matter more than IQ. New York: Bantam Books.

Goleman, D. (1996). Emotional intelligence: The 10th anniversary edition. New York, Bantam Books.

Harrison, R. (1997). Why your firm needs emotional intelligence. People Management, 3(1), 41.

Höpfl, H., \& Linstead, S. (1997). Introduction. Management Learning, 28(1), 5-12.

Martinez-Pons, M. (1997). The relation of emotional intelligence with selected areas of personal functioning. Imagination, Cognition and Personality, 17, 3-14.

Mezirow, J. (1991). Transformative dimensions of adult learning. San Francisco: Jossey-Bass.

Patton, M. Q. (2002). Qualitative research and evaluation methods ( ${ }^{\text {rd }}$ ed.). Thousand Oaks, CA: Sage.

Pearman, R. (2002). Introduction to type and emotional intelligence: Pathways to performance, Palo Alto, CA. CPP, Inc.

Rubin, R. S., Munz, D. C., \& Bommer, W. H. (2005). Leading from within: The effects of emotion recognition and personality on transformational leadership behavior. Academy of Management Journal, 48(5), 845-858.

Salovey, P., \& Mayer, J. D. (1990). Emotional intelligence. Imagination, Cognition and Personality, 9(3), 185-211.

Slaski, M., \& Cartwright, S. (2002). Health, performance and emotional intelligence: An exploratory study of retail managers. Stress and Health, 18(2), 63-68.

Steiner, C., \& Perry, P. (1997). Achieving emotional literacy: A personal program to increase your emotional intelligence. New York: Avon Books.

Tashakkori, A., \& Teddlie, C. (1998). Mixed methodology: Combining qualitative and quantitative approaches. Thousand Oaks, CA: Sage.

Tierney, P., Farmer, S., \& Graen, G. (1999). An examination of leadership and employee creativity: The relevance of traits and relationships. Personnel Psychology, 52, 591-620. 


\section{Author Biographies}

Michael Liepold is an Extension Professor in Leadership and Civic Engagement with the University of Minnesota. He serves as program leader for the Minnesota Agriculture and Rural Leadership Program which served as the basis for this research. His primary work is the development of skilled leaders for rural Minnesota. In addition to his research and application of emotional intelligence in a cohort learning environment, he has demonstrated experience in educational program development, program evaluation, and teaching.

Catherine Rasmussen is an Extension Professor in Leadership and Civic Engagement with the University of Minnesota. Rasmussen is the primary designer of bridging leadership program initiatives for Minnesota counties. Her work focuses on building leadership capacity and enhancing collaboration skills of communities, elected officials, and local organizations to collectively address public issues. In addition to current research on enhancing emotional intelligence, Rasmussen's interest focuses on the theory of change for communities.

Kim Boyce is a Regional Extension Director in the metropolitan area of Minnesota. He previously served as an Extension Professor in Leadership and Civic Engagement with the University of Minnesota where he designed and taught numerous regional and state leadership programs. His current responsibilities have him frequently utilizing research and application of emotional intelligence, critical thinking, and process redesign with public sector leaders and managers.

Denise Trudeau Poskas is a Leadership Specialist for the Center for Community Vitality with the University of Minnesota. She provides staff development, research, and analysis in the areas of organizational and community leadership impacts and programs. Her research interests include positive psychology, systematic change, and leadership program design and development. With over 10 years in leadership coaching and 20 years teaching at the university level in leadership, she strives to use this experience to create strong leadership programs. 